\title{
Broadband semiconductor optical amplifiers and tunable semiconductor lasers
}

\author{
${ }^{\text {a, b, c }}$ Ching-Fuh Lin, ${ }^{\text {a }}$ Yi-Shin Su, ${ }^{\text {a }}$ Fei-Hung Chu, and ${ }^{\mathrm{d}}$ Chia-Wei Tsai \\ ${ }^{a}$ with Graduate Institute of Electro-Optical Engineering \\ ${ }^{\mathrm{b}}$ with Department of Electrical Engineering \\ ${ }^{c}$ with Graduate Institute of Electronics Engineering \\ ${ }^{d}$ with Department of Physics \\ National Taiwan University, Taipei, Taiwan
}

\begin{abstract}
Nonidentical multiple quantum wells (MQWs) had been widely used for broadening the emission or gain bandwidth of semiconductor optical amplifiers (SOAs). However, the carrier distribution among the MQWs is not uniform, leading to nonuniform gain contributed from different QWs. Thus using nonidentical MQWs for broadband purpose is not intuitively straightforward. Several factors need to be carefully considered. Those factors include the QW sequence, electron/hole transport time across the separate confinement hetero-structure, as well as carrier capture time. In this work, we will discuss the design of MQWs for broadband SOAs. With properly designed nonidentical MQWs, the emission bandwidth could be nearly $400 \mathrm{~nm}$. Also, the tuning range of semiconductor lasers could be extended to be over $200 \mathrm{~nm}$.
\end{abstract}

Keywords: semiconductor optical amplifiers, carrier distribution, broadband, nonidentical multiple quantum wells, quantum-well sequence, separate confinement hetero-structure, emission bandwidth

\section{INTRODUCTION}

Broadband characteristics of semiconductor optical amplifiers (SOAs) and tunable semiconductor lasers are useful for applications in areas such as optical communication, spectroscopy, and interferemetric tomography. For optical communication, the optical fiber exhibits very broad bandwidth, almost covering the range from $1.2 \mu \mathrm{m}$ to $1.6 \mu \mathrm{m}$ with a loss of less than $1 \mathrm{~dB} / \mathrm{km}$. Optical-fiber communication therefore requires components and systems to have similar broadband characteristics. However, Er-doped fiber amplifiers and lasers provide a bandwidth much less than the available range of optical fibers. Semiconductor lasers/amplifiers using multiple-quantum-well (MQW) engineering thus provide another possibility for the broadband purpose. In addition, they are of compact size and can be directly integrated with electronic components, making them more attractive than other types of devices for the same purpose.

Conventional SOAs usually have a bandwidth of less than $50 \mathrm{~nm}$. To cover the entire usable bandwidth of an optical fiber, many conventional SOAs having different spectral ranges are required. If the bandwidth of SOAs could be broadened, they will be even more attractive. Many methods can be used to broaden the bandwidth of SOAs. One is using simultaneous transitions of several quantized levels in a quantum well. ${ }^{1,2}$ However, simultaneous transitions of different quantized levels can occur only when band-filling effect is obvious at high injection current. In addition, the resulting bandwidth highly depends on the device length, which influences the required population for a certain gain or lasing condition. The other method is to use multiple quantum wells (MQW) of different types. ${ }^{3-7}$ Unfortunately, carriers mainly populate in certain quantum wells only. The nonuniform carrier distribution leads to the gain bandwidth not contributed from every quantum well ${ }^{8-11}$ and so makes the design of multiple quantum wells for broadband purpose not straightforward.

In this paper, we report the influential factors on the emission characteristics of SOAs. With proper design of nonidentical multiple quantum wells (MQW), the emission spectrum could be very broad. The spectral width is nearly $400 \mathrm{~nm}$, covering almost from $1250 \mathrm{~nm}$ to $1650 \mathrm{~nm}$. Very broadly tunable semiconductor lasers can also be achieved with the broadband SOAs as the gain media. The tuning range can be easily more than $200 \mathrm{~nm}$. The detailed physics to achieve the broadband characteristics will be discussed. 


\section{CARRIER DISTRIBUTION IN MULTIPLE QUANTUM WELLS}

The carrier distribution had been theoretically analyzed. Coupled velocity equations were used to predict the carrier dynamics. ${ }^{12}$ Electrons and holes are injected from the $n$-cladding layer and the p-cladding layer, respectively. Therefore, electrons tend to be first captured by the QWs near the n-cladding layer, while holes have the opposite tendency. However, the charge neutrality requires that both electrons and holes have similar distribution in the multiple quantum wells. The theory expected that carriers did not distribute uniformly in the multiple quantum wells and their distribution favored the p-side. The calculated results are shown in Fig. $1 .{ }^{8}$ Many studies had obtained the similar results. ${ }^{9}, 10,13-15$

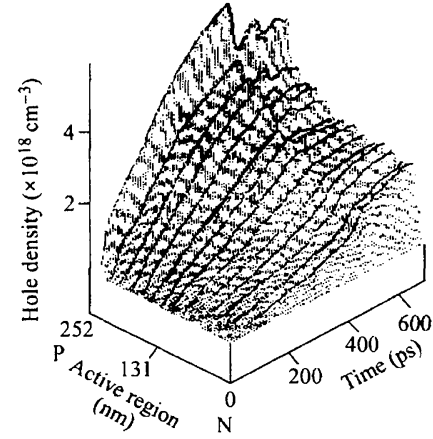

(a)

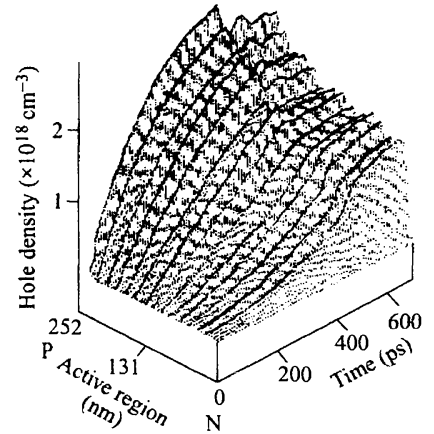

(b)

Fig. 1 Calculation of electrons' and holes' distribution in the 14 layers of quantum wells. It shows highly uneven-distribution properties. ${ }^{8}$

The reason for carrier distribution favoring the QWs near the p-cladding is explained as follows. Because holes have much smaller mobility than electrons, they move much slower than electrons. When they are near the quantum-well region, a strong electric field is built between electrons and holes. The electric field then tends to pull electrons toward holes because of the high mobility of electrons. Therefore, electrons are forced to move from the n-cladding to the QWs near the p-cladding layer to satisfy charge neutrality. Moreover, because the electrons have longer capture time and shorter diffusion time, it is easier for electrons to reach the positions of holes. However, the above concept could not explain our experiment that showed more carriers in QWs near n-side than near p-side. It will be described in the following.

\section{SEQUENCE INFLUENCE ON CARRIER DISTRIBUTION AMONG MQWS}

The sequence of MQWs had been found to strongly influence the bandwidth of SOAs. ${ }^{16}$ Mirror-imaged MQWs of different types were used for the experiment. We used two MQW structures with the same MQWs, but opposite sequence of $\mathrm{QW}$ layout. The quantum-well structures have two $\mathrm{In}_{0.53} \mathrm{Ga}_{0.47} \mathrm{As} \mathrm{QWs}$ and three $\mathrm{In}_{0.67} \mathrm{Ga}_{0.33} \mathrm{As}_{0.72} \mathrm{P}_{0.28} \mathrm{QWs}$. The QWs are separated by wide $\mathrm{In}_{0.86} \mathrm{Ga}_{0.14} \mathrm{As}_{0.3} \mathrm{P}_{0.7}$ barriers. The $\mathrm{In}_{0.53} \mathrm{Ga}_{0.47} \mathrm{As}$ QWs are $8.7 \mathrm{~nm}$ wide, while the $\mathrm{In}_{0.67} \mathrm{Ga}_{0.33} \mathrm{As}_{0.72} \mathrm{P}_{0.28} \mathrm{QWs}$ are $6 \mathrm{~nm}$ wide. The first sequence has the two $\mathrm{In}_{0.53} \mathrm{Ga}_{0.47} \mathrm{As} \mathrm{QWs}$ near the n-cladding layer and the three $\mathrm{In}_{0.67} \mathrm{Ga}_{0.33} \mathrm{As}_{0.72} \mathrm{P}_{0.28} \mathrm{QWs}$ near the p-cladding layer, as shown in Fig. 2. The second sequence has the opposite layout, i.e., the two $\mathrm{In}_{0.53} \mathrm{Ga}_{0.47} \mathrm{As} \mathrm{QWs}$ near the p-cladding layer and the three $\operatorname{In}_{0.67} \mathrm{Ga}_{0.33} \mathrm{As}_{0.72} \mathrm{P}_{0.28} \mathrm{QWs}$ near the n-cladding layer. The QW structure was grown using MOCVD. Bent-stripe ridge-waveguide SOAs were fabricated on those substrates. ${ }^{17}$ The device length is about $500 \mu \mathrm{m}$. Typical processing techniques were used for the device fabrication. The ridge waveguide was created by RIE. No facet coatings were applied to the devices.

Figs. 3 (a) and (b) show the measured emission spectra of the three samples for different injection-current levels. Very distinct features of the emission spectra from the two samples of opposite QW sequence are clearly shown in Figs. 3(a) and (b). For the sample of the first QW sequence shown in Fig. 2, the emission at the low injection current occurs at the wavelength corresponding to the $\mathrm{n}=1$ transition in the $8.7 \mathrm{~nm} \mathrm{In}{ }_{0.53} \mathrm{Ga}_{0.47} \mathrm{As}$ QWs. As the injection current slightly increases, the emission spectrum is then contributed from the simultaneous transitions of $n=1$ and $n=2$ states in the same QWs. The emission due to the $6 \mathrm{~nm} \operatorname{In}_{0.67} \mathrm{Ga}_{0.33} \mathrm{As}_{0.72} \mathrm{P}_{0.28} \mathrm{QWs}$ is not obvious until the injection current increased to above $400 \mathrm{~mA}$. For the sample of the second QW sequence, the emission at the low injection current occurs at the wavelength corresponding to the $\mathrm{n}=1$ transition in the $6 \mathrm{~nm} \mathrm{In}_{0.67} \mathrm{Ga}_{0.33} \mathrm{As}_{0.72} \mathrm{P}_{0.28}$ QWs. Further increase of the injection 
current does not obviously change the emission wavelength. The slight blue-shift of the peak wavelength is a result of the band-filling effect in the $\operatorname{In}_{0.67} \mathrm{Ga}_{0.33} \mathrm{As}_{0.72} \mathrm{P}_{0.28}$ QWs. As we compare the emission spectra from the two samples, it is clear that the first QW sequence has much broader spectral width than the second QW sequence.

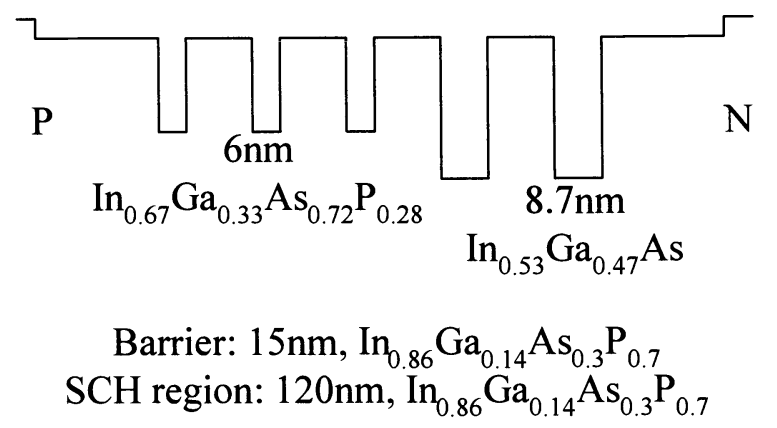

Fig. 2 Schematic of QW structure nonidentical MQWs for the study of QW sequence influence on SOA bandwidth.
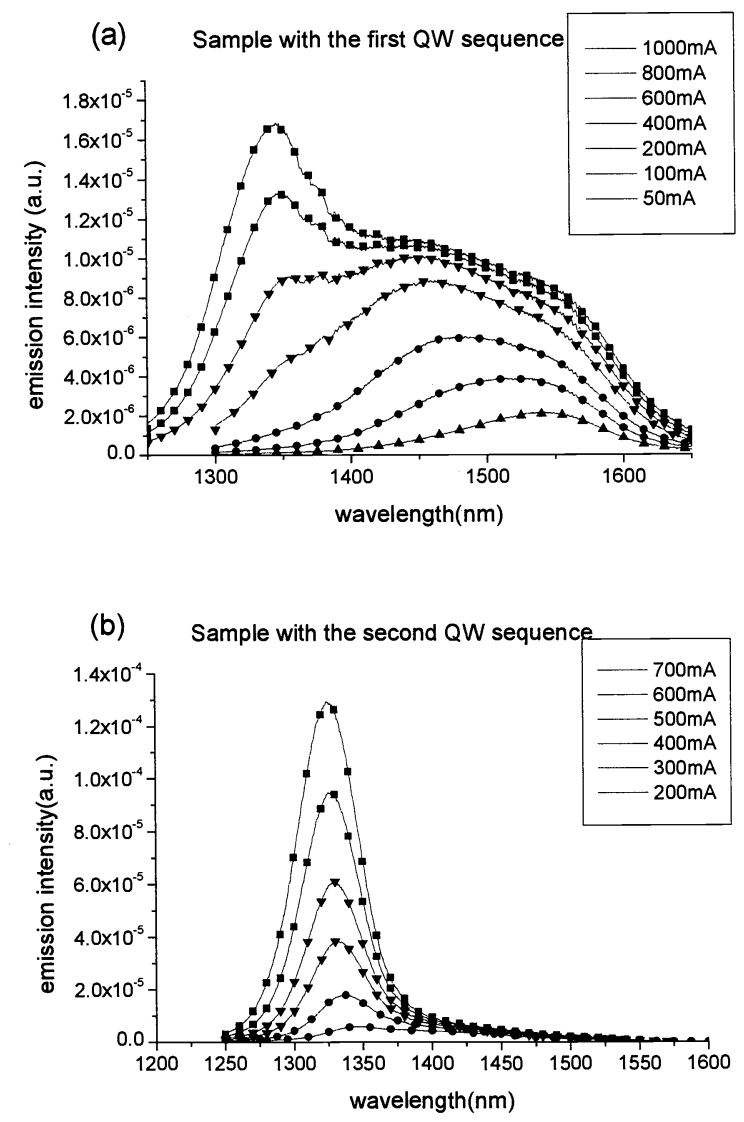

Fig. 3 The emission spectra at different injection currents: (a) the first QW sequence shown in Fig. 1; (b) the second QW sequence opposite to the first $\mathrm{QW}$ sequence.

For the first QW sequence, the $8.7 \mathrm{~nm} \mathrm{In}_{0.53} \mathrm{Ga}_{0.47} \mathrm{As} \mathrm{QWs}$ are near the n-cladding layer. For the second QW sequence, the $6 \mathrm{~nm} \mathrm{In}{ }_{0.67} \mathrm{Ga}_{0.33} \mathrm{As}_{0.72} \mathrm{P}_{0.28}$ QWs are near the n-cladding layer. The measured spectra from the above samples show that the wells near the n-cladding layer accumulate more carriers than those near the p-cladding layer, 
which is different from past observations. ${ }^{9,11}$ In the past, the slow mobility of holes is deemed to be the reason for the nonuniform carrier distribution and leads to the carriers favoring QWs near the p-cladding layer. However, our new discovery shows that other factors could be influential as well and may be more important than the slow movement of holes. Therefore, we obtained the behaviors opposite to the past observation.

\section{INFLUENTIAL FACTORS ON CARRIER DISTRIBUTION AMONG MQWS}

Many factors have been studied to show their influences on the carrier distribution. Here we would like to address a new point of view. We assert that the type of carriers first arriving at the QWs will determine the carrier distribution. The reason is as follows. In the carrier injection, electrons and holes move from the n-cladding layer and the p-cladding layer, respectively. If electrons arrive at the QWs much earlier than holes, they will be captured in QWs nearest to n-cladding. At this time, holes are still far away from QW region, so electrons and holes are far apart. This leads to two effects. First, the band tilt across the separate confinement hetero-structure (SCH) layer and the QW region is small. Second, the electric field between the electrons and the holes is still small, so electrons are not significantly influenced by holes. As time goes on, holes continue to move toward QWs. When holes are close to QWs, the distance between the hole cluster and the electron cluster is very short. Thus the_band tilt is large. It means that the electric field is strong and holes tend to be pulled toward electrons instead of being captured into QWs near the p-cladding. This mechanism causes holes to follow the electron distribution to achieve the condition of quasi-charge neutrality. Therefore, carrier distribution favors QWs near the n-cladding layer. On the other hand, if holes arrive at the QWs first, carrier distribution favors Qws near the p-cladding layer.

The overall effect depends on the summation of the diffusion time across the SCH layer and the capture time. The diffusion time is given by $d^{2} / 4 D$, where $d$ is the thickness of SCH layer and $D$ is the diffusion constant. The capture time for electrons and holes is about $1 \mathrm{ps}\left(\tau_{c n}\right)$ and $0.2 \mathrm{ps}\left(\tau_{c p}\right)$, respectively. ${ }^{18,19}$ Because our layer structures have a very thick SCH layer, the hole diffusion time is about $11 \mathrm{ps,} \mathrm{which} \mathrm{is} \mathrm{much} \mathrm{longer} \mathrm{than} \mathrm{the} \mathrm{sum} \mathrm{of} \mathrm{the} \mathrm{electron}$ diffusion time and the electron capture time. Thus electrons reside in the QWs before holes, leading to carrier distribution favoring QWs near the n-cladding layer.

The influence of $\mathrm{SCH}$ layer thickness on the carrier distribution has also been experimented. We designed samples with the same nonidentical MQWs, but the QW structures have different SCH layer thickness. SOAs/SLDs were fabricated on the substrates with those QW structures. The measurements of emission spectra show that the thinner SCH layer has broader emission spectra. This further confirms that the transport time of carriers across the $\mathrm{SCH}$ layer has very strong influence on the carrier distribution. Our discovery suggests that carrier distribution can be engineered to favor carriers in QW near the n-cladding layer, the p-cladding layer, or equally among QWs.

\section{MQW STRUCTURE FOR BROADBAND EMISSION SPECTRA}

With the above knowledge, we are able to design MQW structure that exhibits extremely broadband characteristics. The layer structure is shown in Fig. 4. Compared to the previous structure, the two $\operatorname{In}_{0.53} \mathrm{Ga}_{0.47}$ As quantum wells are designed to be $150 \AA$, so the emission could extend to wavelength longer than $1.55 \mu \mathrm{m}$. They are grown near the n-cladding layer. For short-wavelength side, we used five $60 \AA \operatorname{In}_{0.67} \mathrm{Ga}_{0.33} \mathrm{As}_{0.72} \mathrm{P}_{0.28}$ quantum wells in order to compensate the possible absorption by the two $\mathrm{In}_{0.53} \mathrm{Ga}_{0.47} \mathrm{As}$ quantum wells. They are grown near the p-cladding layer. $\mathrm{In}_{0.86} \mathrm{Ga}_{0.14} \mathrm{As}_{0.3} \mathrm{P}_{0.7}$ barriers of $150 \AA$ width are used to separate those $\mathrm{QWs}$. The sequence of QW layout is the same as the previous design ${ }^{16}$ for better uniformity of carrier distribution among MQWs.

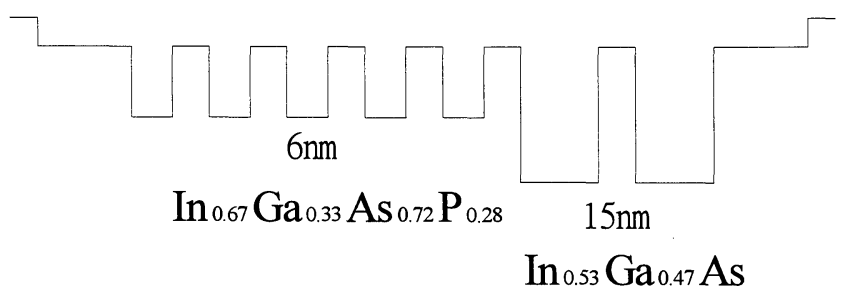

Fig. 4 Quantum-well structure of designed MQWs for broadband emission.

The designed nonidentical MQW structure was then grown on InP substrate by MOCVD. Both bent-waveguide ${ }^{17}$ 
and tilted-stripe SLDs ${ }^{20}$ had been fabricated using typical processing techniques. With those structures, the Fabry-Perot resonance could be minimized, so the emission spectrum can be directly realized. The ridge waveguide was created by $\mathrm{RIE}$ and etching was stopped at $\sim 100 \mathrm{~nm}$ above the separate confinement hetero-structure (SCH) layer. The fabrication is completed by $\mathrm{n}$-contact metallization and then the devices were cleaved apart. No facet coatings were applied to the devices.

The emission spectra of the fabricated devices in different current levels were measured and shown in Fig. 5. Both the bent-waveguide SLDs and the tilted-stripe SLDs behave similarly. The emission at the low injection current first occurs at the wavelength corresponding to the $\mathrm{n}=1$ transition in the $150 \AA \mathrm{In}_{0.53} \mathrm{Ga}_{0.47} A s$ double QWs. However, the emission from the five $60 \AA \mathrm{In}_{0.67} \mathrm{Ga}_{0.33} \mathrm{As}_{0.72} \mathrm{P}_{0.28}$ QWs already appears even at the low injection current of $100 \mathrm{~mA}$. As injection current increases, emission contributed from the $60 \AA \mathrm{In}_{0.67} \mathrm{Ga}_{0.33} \mathrm{As}_{0.72} \mathrm{P}_{0.28} \mathrm{QW}$ grows faster than that contributed from the $\mathrm{In}_{0.53} \mathrm{Ga}_{0.47} \mathrm{As} \mathrm{QWs}$, so the spectrum is very broad. The emission spectrum continues to broaden as the injection current increases. The spectral width is plotted against the injection current in Fig. 6. The FWHM of the spectrum is already more than $200 \mathrm{~nm}$ for the injection current below $100 \mathrm{~mA}$ and increases fast for current up to $400 \mathrm{~mA}$. After this current level, the $\mathrm{In}_{0.53} \mathrm{Ga}_{0.47} \mathrm{As}$ QWs are filled with carriers. As a result, the emission from the $\mathrm{In}_{0.67} \mathrm{Ga}_{0.33} \mathrm{As}_{0.72} \mathrm{P}_{0.28} \mathrm{QWs}$ is not absorbed by the $\mathrm{In}_{0.53} \mathrm{Ga}_{0.47} \mathrm{As} \mathrm{QWs}$. Further injection of carriers then stay in $\mathrm{In}_{0.67} \mathrm{Ga}_{0.33} \mathrm{As}_{0.72} \mathrm{P}_{0.28} \mathrm{QWs}$, causing the corresponding emission of light to increase fast with the injection current. Therefore, the spectrum is very broad. The maximum FWHM spectral width is near $400 \mathrm{~nm}$, covering from $1252 \mathrm{~nm}$ to $1643 \mathrm{~nm}$.

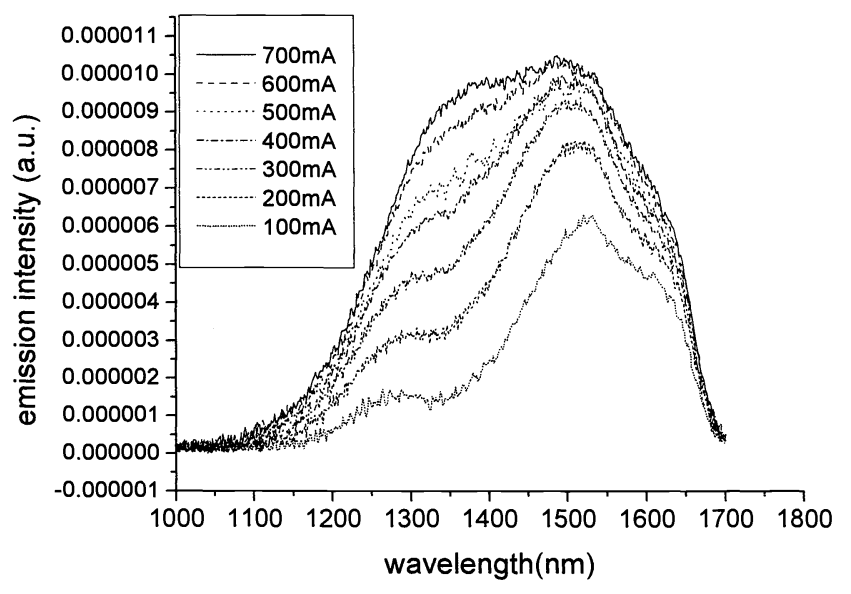

Fig. 5 The emission spectra at different injection current levels.

The FWHM of the emission spectrum from the previous MQW structure ${ }^{16}$ is also plotted in Fig. 6 for comparison. The previous MQW structure has gradual increase of spectral width. Its maximum spectral width is only around $300 \mathrm{~nm}$ at the injection current of $600 \mathrm{~mA}$ (curve (b) of Fig. 6). In comparison, Curve (a) in Fig. 6 shows that the spectral width has rapid increase for current below $400 \mathrm{~mA}$. At current of $\sim 250 \mathrm{~mA}$, the spectral width already reaches $300 \mathrm{~nm}$. The maximum spectral width is about $400 \mathrm{~nm}, 30 \%$ more than the previous MQW structure. The fast increase of spectral width at low injection indicates that the $\mathrm{QW}$ structure shown in Fig. 4 could have carriers reside in $\operatorname{In}_{0.67} \mathrm{Ga}_{0.33} \mathrm{As}_{0.72} \mathrm{P}_{0.28}$ QWs at low injection carriers. Thus the uniformity of carrier distribution is improved. The less measured emission at the short-wavelength side is because its corresponding energy is large and the emission can be absorbed by the $\mathrm{In}_{0.53} \mathrm{Ga}_{0.47} \mathrm{As} \mathrm{QWs}$.

If the number of $\operatorname{In}_{0.67} \mathrm{Ga}_{0.33} \mathrm{As}_{0.72} \mathrm{P}_{0.28} \mathrm{QWs}$ is further increased, the broad spectrum should be achieved at even lower operation current. However, the sequence of QW layout still needs to be carefully considered, so carriers will reside in the $150 \AA \operatorname{In}_{0.53} \mathrm{Ga}_{0.47} \mathrm{As} \mathrm{QWs}$, which contribute to the long-wavelength emission.

\section{BROADLY TUNABLE SEMICONDUCTOR LASERS}

In this section, we will report and discuss the possibility of using the above broadband SOAs as the gain media to achieve the broadband tuning of semiconductor lasers. 


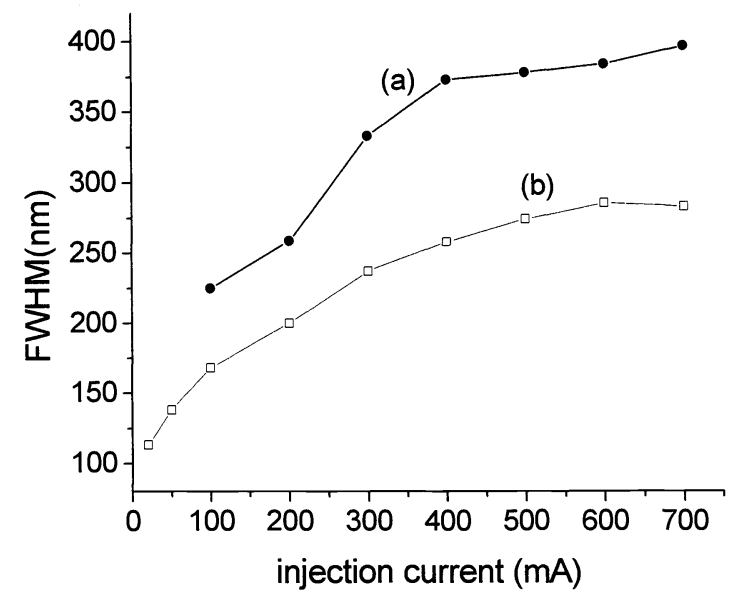

Fig. 6 Spectral width vs. injection current: (a) MQW structure shown in Fig. 4; (b) MQW structure shown in Fig. $1 .^{16}$

\subsection{Influence of $Q W$ sequence on the tuning range}

The influence of QW sequence on the carrier distribution among the MQWs had been reported in Sec. 3. For the well sequence shown in Fig. 2, we can have carriers distributing among the two types of QWs, which have their $n=1$ transition corresponding to wavelengths of $1.3 \mu \mathrm{m}$ and $1.55 \mu \mathrm{m}$, respectively. The total gain spectrum can then cover the range from below $1.3 \mu \mathrm{m}$ to above $1.55 \mu \mathrm{m}$, depending on the injection current according to the calculation using Luttinger-Kohn method. ${ }^{21,22}$ In contrast, for the QW sequence opposite to the one shown in Fig. 2, carriers distribute mostly in the $6 \mathrm{~nm} \mathrm{In}_{0.67} \mathrm{Ga}_{0.33} \mathrm{As}_{0.72} \mathrm{P}_{0.28}$ QWs. Therefore, its gain spectrum covers the range mainly around $1.3 \mu \mathrm{m}$. The SOAs with the two different QW sequences are used in the external-cavity configuration for tuning experiment. The cavity configuration is shown in Fig. 7. The bending side of the waveguide in the SOA faces the grating. Light emitted from the facet is collimated and delivered to the grating. The output light is taken from the straight side of the waveguide and collimated. Tuning is achieved by rotating the grating.

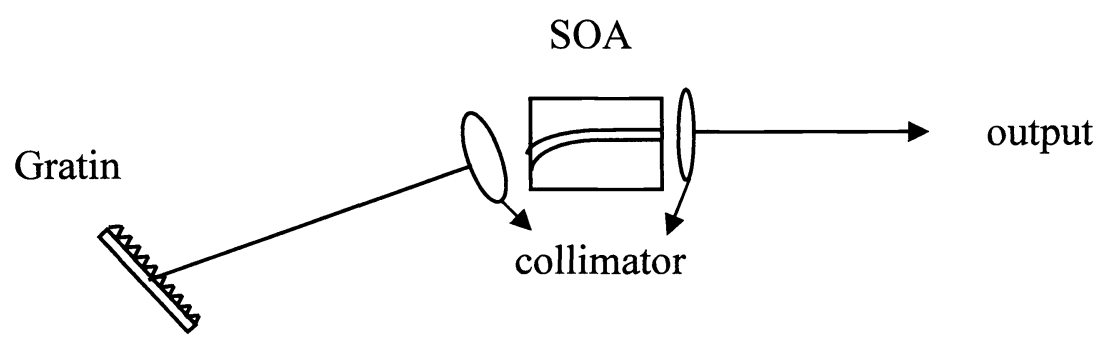

Fig. 7 Tunable semiconductor laser with an external-cavity configuration.

When the SOA with the QW sequence shown in Fig.2 is used in the cavity, the tuning range is very broad. Fig. 8 (a) shows the threshold current vs. the tuning wavelength. The wavelength is tunable from $1300 \mathrm{~nm}$ to $1540 \mathrm{~nm}$ with a range of $240 \mathrm{~nm}$. The experiment confirms that the SOA could provide gain for the same broad spectral range. On the other hand, if the SOA with the opposite QW sequence is used in the cavity, the tuning range is much narrower. It is now tunable from $1290 \mathrm{~nm}$ to $1450 \mathrm{~nm}$ with a range of $160 \mathrm{~nm}$. The tuning range extends slightly further toward the short wavelength side because carriers now more concentrate on the $6 \mathrm{~nm} \mathrm{In}_{0.67} \mathrm{Ga}_{0.33} \mathrm{As}_{0.72} \mathrm{P}_{0.28} \mathrm{QWs}$. However, tuning toward the long wavelength side is severely limited due to the negligible carriers in the $\mathrm{In}_{0.53} \mathrm{Ga}_{0.47} \mathrm{As} \mathrm{QWs}$. This indicates that the SOAs with the opposite QW sequence only provide gain for the short wavelength. 
(a)

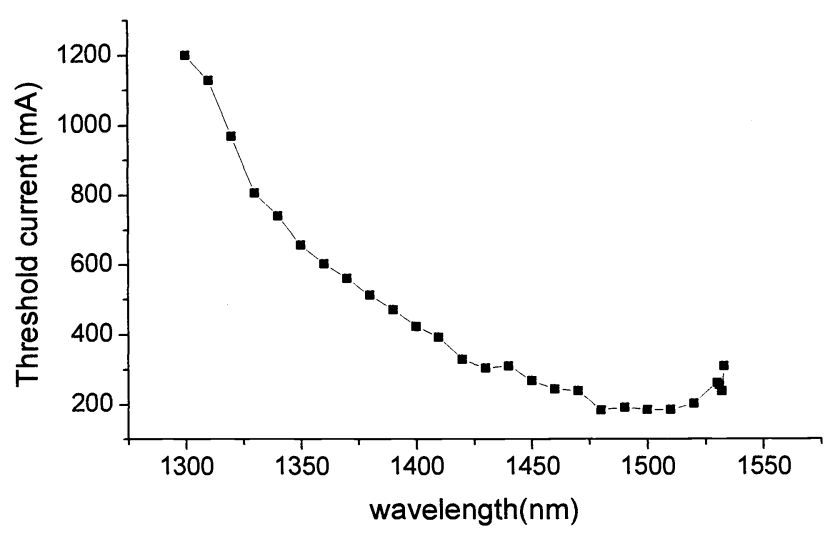

(b)

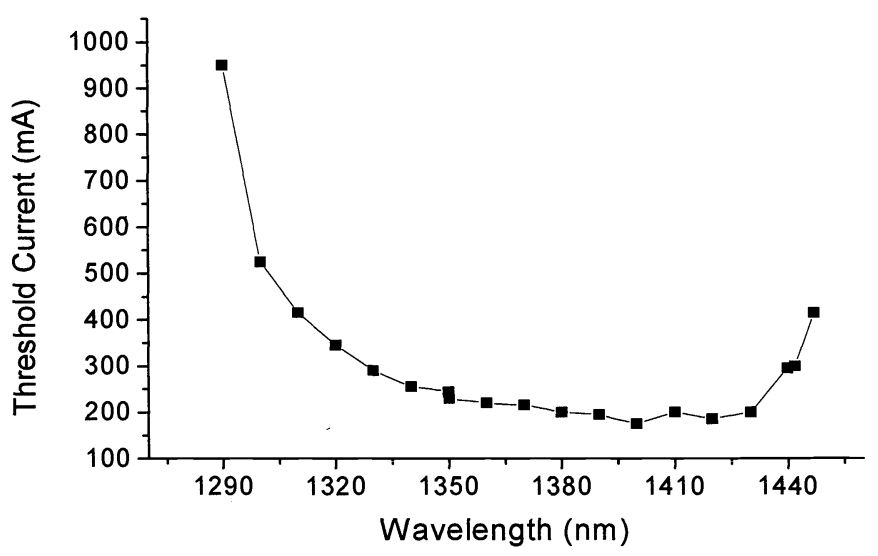

Fig. 8 Threshold current vs. tuning wavelength for using SOA with (a) QW sequence shown in Fig. 2 and (b) QW sequence opposite to Fig. 2.

\subsection{Broadly tunable semiconductor lasers with reduced operation}

Fig. 8(a) shows that very broadband tuning can be achieved using SOAs with properly designed nonidentical QW structure. The tuning range is $240 \mathrm{~nm}$. However, the operation current is quite large. The reason is due to the bending waveguide structure, which induces two effects. First, the bending waveguide has more loss than the usual straight waveguide. Second, the light field may not be properly guided in the waveguide, leading to extra loss for coupling to the external cavity. ${ }^{23}$ To confirm the possible reduction of operation current, we use the Fabry-Perot laser diode (LD) in the external cavity for tuning experiment. Again, the external cavity has a grating for the control of tuning wavelength.

The Fabry-Perot LD has the same QW structure shown in Fig. 2. Ridge-waveguide LDs were fabricated on the substrate. The ridge width is about $3 \mu \mathrm{m}$ and the device length is $300 \mu \mathrm{m}$. No AR-coating is applied, so the device oscillates at the current of $\sim 120 \mathrm{~mA}$. The lasing wavelength is about $1360 \mathrm{~nm}$. The short wavelength indicates that the current level is already large enough to shift the gain peak from the $n=1$ transition of the $\operatorname{In}_{0.53} \mathrm{Ga}_{0.47} \mathrm{As}$ QWs to the $n=2$ transition. In addition, carriers probably also distribute in the $\mathrm{In}_{0.67} \mathrm{Ga}_{0.33} \mathrm{As}_{0.72} \mathrm{P}_{0.28} \mathrm{QWs}$, so the gain at the short wavelength is increased to above the loss. When the LD is set up in the external cavity, additional feedback of light is delivered to the LD, so the loss level is reduced. This will cause the lasing threshold to reduce. Furthermore, the gain peak changes with the injection current, so the threshold varies with the lasing wavelength. In this way, we are able to use the uncoated Fabry-Perot LD in the external cavity to achieve broadband tuning. The threshold current vs. the tuning wavelength is shown in Fig. 9. The wavelength is tunable from $1344 \mathrm{~nm}$ to $1561 \mathrm{~nm}$. The threshold current is below $116 \mathrm{~mA}$ for the tuning range of $217 \mathrm{~nm}$. The minimum threshold current is $28.5 \mathrm{~mA}$ at the wavelength of 1530 $\mathrm{nm}$. 


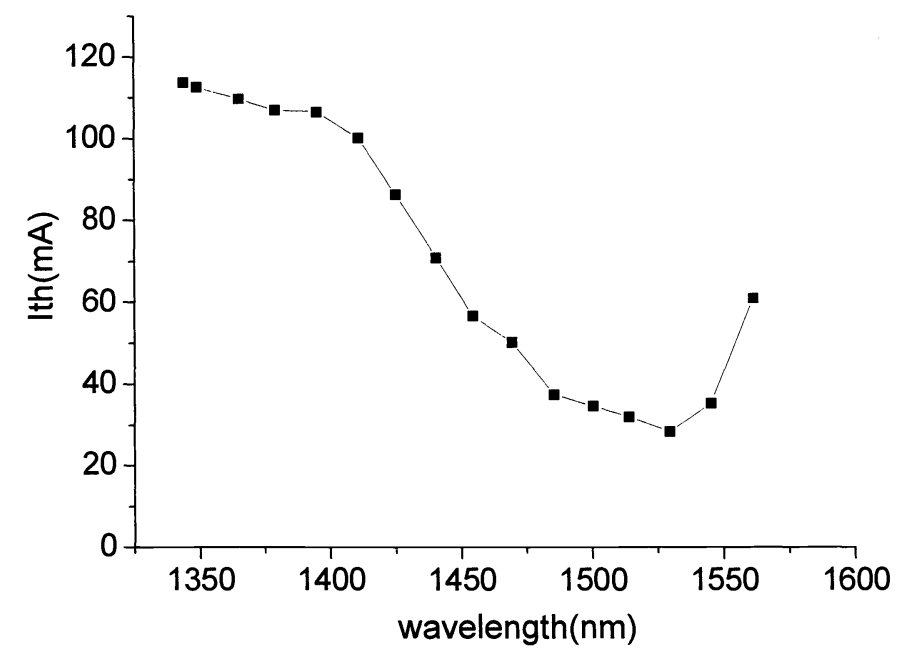

Fig. 9 Threshold current vs. tuning wavelength using the Fabry-Perot LD in the external cavity.

\section{CONCLUSION}

In conclusion, the physics of carrier distribution among the MQWs are studied in detail. We discovered that carriers can distribute more in the QWs near the n-cladding layer than near the p-cladding layer. The reason is because the carrier is not determined solely by holes. Electrons can be dominant in the carrier distribution, too. The situation can be controlled by the layer structure of MQWs. Thus carrier distribution is possibly engineered. With properly design of MQWs, we are able to achieve broadband emission using two properly designed $150 \AA \operatorname{In}_{0.53} \mathrm{Ga}_{0.47} \mathrm{As}$ QWs and five $60 \AA \operatorname{In}_{0.67} \mathrm{Ga}_{0.33} \mathrm{As}_{0.72} \mathrm{P}_{0.28}$ QWs. A spectral width covering a range from $1.25 \mu \mathrm{m}$ to $1.65 \mu \mathrm{m}$ has been achieved. The spectral width could be near $400 \mathrm{~nm}$. When the SOAs with broadband characteristics are used in the external cavity, the semiconductor laser is broadly tunable. The tuning range is from $1300 \mathrm{~nm}$ to $1540 \mathrm{~nm}$ using bending-waveguide SOAs in the cavity. However, the operation current is high due to the loss induced by the bending waveguide. If a Fabry-Perot LD with the same QW structure is used in the external cavity, the operation current is greatly reduced to below $116 \mathrm{~mA}$. The tuning range is still over $200 \mathrm{~nm}$. The minimum threshold current can be as low as $28.5 \mathrm{~mA}$.

\section{REFERENCES}

1. T. R. Chen, L. Eng., Y. H. Zhuang, and A. Yariv, "Quantum well superluminescent diode with very wide emission spectrum," Appl. Phys. Lett. vol. 56, pp. 1345-1346, 1990.

2. T. Semenov, V. R. Shidlovski, and S. A. Safin, "Wide spectrum single quantum well superluminescent diodes at $0.8 \mu \mathrm{m}$ with bent optical waveguide," Electron. Lett., vol. 29, pp. 854-857, 1993.

3. Ching-Fuh Lin, Bor-Lin Lee, and Bor-Jian Lin, "Broad-band superluminescent diodes fabricated on a substrate with asymmetric dual quantum wells," IEEE Photon. Technol. Lett., vol. 8, pp. 1456-1458, 1996.

4. X. Zhu, D. Cassidy, M. Hamp, D. Thompson, B. Robinson, Q. Zhao, and M. Davies, "1.4- $\mu \mathrm{m}$ InGaAsP-InP strained multiple-quantum-well laser for broad-wavelength tenability," IEEE Photon. Technol. Lett., vol. 9, pp. 1202-1204, 1997.

5. H. S. Gingrich, D. R. Chumney, S.-Z. Sun, S. D. Hersee, L. F. Lester, and S. R. Brueck, "Broadly tunable external cavity laser diodes with staggered thickness multiple quantum wells," IEEE Photon. Technol. Lett., vol. 9, pp. 155-157, 1997.

6. Ching-Fuh Lin and Bor-Lin Lee, "Extremely broadband AlGaAs/GaAs superluminescent diodes," Appl. Phys. Lett., vol. 71, pp. 1598-1600, 1997.

7. Bing-Ruey Wu, Ching-Fuh Lin, Lih-Wen Laih and Tien-Tsorng Shih, "Extremely Broadband InGaAsP/InP Superluminescent Diodes, " IEE Electron. Lett. 36, pp. 2093-2095, 2000.

8. N. Tessler and G. Eisenstein, "On carrier injection and gain dynamics in quantum well lasers", IEEE J. Quantum Electron., vol. 29, pp.1586-1595, 1993. 
9. H. Yamazaki, A. Tomita, M. Yamaguchi, and Y. Sasaki, "Evidence of nonuniform carrier distribution in multiple quantum well lasers," Appl. Phys. Lett. 71, pp. 767-769, 1997.

10. J. Piprek, P. Abraham, and J. E. Bowers, "Carrier nonuniformity effects on the internal efficiency of multipquantum-well lasers," Appl. Phys. Lett. 74, pp. 489-491, 1999.

11. B. L. Lee, C. F. Lin, J. W. Lai, and W. Lin, "Experimental evidence of nonuniform carrier distribution in multiple-quantum-well laser diodes," Electron. Lett., vol. 34, pp. 1230-1231, 1998.

12. D. Tauber and J. E. Bowers, "Dynamics of wide bandwidth semiconductor lasers," from "High Speed Diode Lasers," Editor: S. A. Gurevich, pp. 1-40, World Scientific, Singapore, 1998.

13. H. Hillmer and S. Marcinkevičius, "Optically detected carrier transport in III/V semiconductor QW structures:

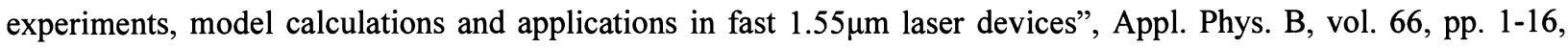
1998.

14. J. Piprek, P. Abraham, and J. E. Bowers, "Carrier nonuniformity effects on the internal efficiency of multiquantum-well lasers", Appl. Phys. Lett., vol. 74, pp. 489-491, 1999.

15. T. C. Newell, M. W. Wright, H. Hou, and L. F. Lester, "Carrier distribution, spontaneous emission and gain engineering in lasers with nonidentical quantum wells", IEEE J. of Selected Topics in Quantum Electron., vol. 5, pp. 620-626, 1999.

16. Ching-Fuh Lin, Bing-Ruey Wu, Lih-Wen Laih, and Tien-Tsorng Shih, "Sequence influence of nonidentical InGaAsP quantum wells on broadband characteristics of semiconductor optical amplifiers/superluminescent diodes," Opt. Lett. 26, pp. 1099-1101, 2001.

17. Ching-Fuh Lin and Chaur-Shiuann Juang, "Superluminescent diodes with bent waveguide", IEEE Photon. Technol. Lett. 8, pp. 206-208, 1996.

18. M. Alam and M. Lundstrom, "Simple analysis of carrier transport and buildup in separate confinement heterostructure quantum well lasers," IEEE Photon. Technol. Lett. 6, pp. 1418-1420, 1994.

19. S. C. Kan, D. Vassilovski, T. C. Wu, and K. Y. Lau, "On the effects of carrier diffusion and quantum capture in high speed modulation of quantum well lasers," Appl. Phys. Lett., 61, pp. 752-754, 1992.

20. G. A. Alphonse, D. B. Gilbert, M. G. Harvey, and M. Ettenberg: "High-power superluminescent diodes," IEEE J. Quantum Electron., 24, pp. 2454-2457, 1988.

21. D. Ahn and S. L. Chuang 'Optical gain and gain suppression of quantum well lasers with valence band mixing', IEEE J. of Quantum Electron., vol. 26, pp. 13-24, 1990.

22. S. L. Chuang 'Physics of Optoelectronic Devices', Chap. 9, John Wiley \& Sons, New York, 1995.

23. Gagik Sh. Shmavonyan, Yi-Shin Su, and Ching-Fuh Lin, "Peculiarities of emission characteristics of semiconductor optical amplifier with multiple quantum wells, "Photonics West 2003, Paper 4986-52, San Jose, USA, 2003. 